ОДИНЦОВА М. А., РАДЧИКОВА Н. П., СТЕПАНОВА Л. В.

ОЦЕНКА ПАНДЕМИИ COVID-19 РОССИЯНАМИ С РАЗНЫМ УРОВНЕМ ЖИЗНЕСТОЙКОСТИ

РосСиЙский психологИчЕский жУРнАл, 2020, Т. 17, № 3, 76-88. doi: 10.21702/rpj.2020.3.6

СОЦИАЛЬНАЯ ПСИХОЛОГИЯ

УдК 159.9.072.43:316.6 doi: $10.21702 /$ rpj.2020.3.6

Оригинальная научная статья

\title{
Оценка пандемии COVID-19 россиянами с разным уровнем жизнестойкости
}

\author{
Мария А. Одинцова ${ }^{*}$, Наталия П. Радчикова', Лариса В. Степанова' \\ ${ }^{1}$ Московский государственный психолого-педагогический университет, г. Москва, Российская \\ Федерация \\ ${ }^{2}$ Московский педагогический государственный университет, г. Москва, Российская Федерация \\ *E-mail: mari505@mail.ru \\ ORCID ID: https://orcid.org/0000-0003-3106-4616, https://orcid.org/0000-0002-5139-8288, \\ https://orcid.org/0000-0001-7969-3038
}

\begin{abstract}
Аннотация
Ввеление. Пандемия COVID-19 преАоставляет возможность Изучить вКАаА психологических характеристик в алаптацию человека к условиям неопределенности. ОАной из таких характеристик является жизнестойкость, АО сих пор вызывающая споры о своей роли в подАержании психического, фризического и социального зАоровья человека.

Метолы. Аля проверки гипотезы о различиях в отношении к ситуации пандемии у лиц с разным уровнем жизнестойкости были использованы краткая версия теста жизнестойкости С. МалАи (в молифрикации Е. Н. Осина и Е. И. Рассказовой) и специальная анкета Аля оценки различных аспектов ситуации: ее характеристик, степени возАействия на сореры жизни, страХов, возможностей Аля СовАаАания (по шкале Аикерта от 0 Ао 10). ИсслеАОвание провоАилось в периол самоизоляции с помощью Google Формы (N = 421; возраст 18-78 ^ет (средний возраст $=40,3 \pm 12,6 \wedge е т ; 81 \%$ женщин).

Результаты. Большинство россиян восприняли ситуацию пандемии в качестве вызова своим возможностям. Группу риска составили $17 \%$ оценивших ее как угрозу, что указывает на необхолимость аАресной психологической помощи, направленной на психологическое просвещение, основанное на результатах научных исследований. Россияне с высокой жизнестойкостью признают неопределенность, сложность ситуации пандемии, но считают ее поАКонтрольной. А^я группы с низкой жизнестойкостью Аанная ситуация яв^яется высоко неопределенной, сложной, непредсказуемой и не подАающейся контролю, оказывающей влияние на фризическую активность и качество социальных контактов. Кроме страхов за своих близких выражен страх будущего.

ОбсужАение результатов. Полученные результаты находятся в согласии с представлениями о жизнестойкости как способности вылерживать стрессовые ситуации, сохраняя внутреннюю сбалансированность без снижения успешности Аеятельности, и свидетельствуют о прогностической ценности Аанного конструкта.
\end{abstract}

\section{КАючевые слова}

пандемия COVID-19, самоизоляция, ситуация неопрелеленности, оценка ситуации, жизнестойкость, страхи, степень возАействия, россияне 
ОДИНЦОва М. А., РАДЧИКОВА Н. П., СТЕПАНОВА Л. В.

ОЦЕНКА ПАНДЕМИИ COVID-19 РОССИЯНАМИ С РАЗНЫМ УРОВНЕМ ЖИЗНЕСТОЙКОСТИ

РосСИЙСКИй пСИХологИЧЕСКИй ЖУРнАл, 2020, Т. 17, № 3, 76-88. doi: 10.21702/rpj.2020.3.6

СОЦИАЛЬНАЯ ПСИХОЛОГИЯ

\section{Основные положения}

$\checkmark$ несмотря на то, что пандемия COVID-19 и введение самоизоляции - сложная комбинация стрессоров, отличающаяся неопределенностью, сложностью и неуправляемостью, большинство россиян восприняли Аанную ситуацию как вызов, открывающий новые возможности, в то время как группу риска составили $17 \%$ опрошенных;

$\checkmark$ россияне с высокой жизнестойкостью эфффективнее справляются с ситуацией неопреде^енности: оценивают свои страхи ниже, а возможности-выше, в отличие от россиян с низкой жизнестойкостью;

> россияне с низкой жизнестойкостью рассматривают пандемию COVID-19 как непосреАственную угрозу; кроме страхов за близких, у них выражен страх будущего.

\section{Для цитирования}

Одинцова, М. А., Радчикова, Н. П. и Степанова, Л. В. (2020). Оценка пандемии COVID-19 россиянами с разным уровнем жизнестойкости. Российский психологический журнал, 17(3), 76-88. doi: 10.21702/ rpj.2020.3.6

Дата получения рукописи: 31.07 .2020 Дата окончания рецензирования: 07.09.2020 Дата принятия к публикации: 12.09.2020

\section{Введение}

Крупные эпидемии всегда были значимыми социокультурными событиями для всех стран. Вновь возникающие инфекции представляют собой большую угрозу в силу растущей мобильности населения, перенаселенности в городах, неблагоприятных экологических изменений и т.д. Новый коронавирус (COVID-19), превратившийся в глобальную пандемию, отличается внезапностью, инфекционной силой вируса, широким охватом населения.

Тревожные сводки в СМИ, ограничения в повседневной жизни и деятельности, неопределенность ситуации неизбежно отражаются на психологическом здоровье общества. Неслучайно в публикациях этого года прослеживаются пристальный интерес к проблематике психологических последствий пандемии и обеспокоенность психологическим здоровьем населения разных стран: Саудовской Аравии (AlHumaid, Ali, \& Farooq, 2020); Чили (CaqueoUrízar et al., 2020); Индии (Iqbal \& Dar, 2020); Испании (Rodríguez-Rey, Garrido-Hernansaiz, \& Collado, 2020); Индонезии (Abdullah, 2020); Италии (Marazziti, Pozza, Di Giuseppe, \& Conversano, 2020); Австралии (Berger \& Reupert, 2020); Вьетнама (Nguyen \& Vu, 2020); Америки (Fitzpatrick, Harris, \& Drawve, 2020); Японии (Shigemura \& Kurosawa, 2020); России (Бойко, Медведева, Ениколопов, Воронцова и Казьмина, 2020; Тхостов и Рассказова, 2020) и т. д. Отмечается, что COVID-19 представляет собой особый случай кумулятивного риска, который будет иметь широкое влияние в долгосрочной перспективе (Estes \& Thompson, 2020; Prime, Wade, \& Browne, 2020; Rodríguez-Rey et al., 2020). Установлено, что пандемия может влиять на обострение личностных и межличностных кризисов (Miller, 2020), рост числа суицидов (Reger, Stanley, \& Joiner, 2020), ухудшение здоровья, нарушение поведения (Faris, 2020), усиление переживаний одиночества (Ng \& Lee, 2019), возникновение ПТСР (Boyraz \& Legros, 2020). В условиях самоизоляции прослеживается рост числа случаев домашнего насилия (Campbell, 2020). Выделены наиболее уязвимые группы, среди которых: одинокие; люди, живущие 
ОДИНЦОвА М. А., РАДЧИКОВА Н. П., СТЕПАНОВА Л. В.

ОЦЕНКА ПАНДЕМИИ COVID-19 РОССИЯНАМИ С РАЗНЫМ УРОВНЕМ ЖИЗНЕСТОЙКОСТИ

Российский психологИЧЕСкИй жУРнАл, 2020, Т. 17, № 3, 76-88. doi: 10.21702/rpj.2020.3.6

СОЦИАЛЬНАЯ ПСИХОЛОГИЯ

в стесненных условиях (Prime et al., 2020); пожилые; лица с инвалидностью; медицинские, социальные работники; женщины (Boyraz \& Legros, 2020).

Несмотря на смещение акцента в исследованиях в сторону негативных последствий пандемии, высказано мнение о том, что данная ситуация дает возможность для перерождения, восстановления, пересмотра ценностей, обновления приоритетов (El Maarouf, Belghazi, \& El Maarouf, 2020). Подчеркивается, что для успешного совладания требуются зрелость (Durodié, 2020), способность придавать смысл непредсказуемым обстоятельствам (Trzebiński, Cabański, \& Czarnecka, 2020), социальная сплоченность и гибкость (Chen \& Bonanno, 2020). Особое внимание уделяется индивидуальной и общественной устойчивости как способности к сопротивлению трудностям (PeConga et al., 2020); обсуждается опыт переживших Холокост, подготовивший пожилых людей к пандемии, несмотря на их особую уязвимость (Cohn-Schwartz, Sagi, O'Rourke, \& Bachner, 2020). Высказывается оптимистичная точка зрения о том, что долговременная устойчивость будет наиболее распространенным результатом даже для тех, кто в наибольшей степени пострадал от COVID-19 (Cohn-Schwartz et al., 2020). С одной стороны, переживание пандемии как угрозы приводит к травматизации и уязвимости, обострению кризисных явлений в обществах; с другой -при восприятии ее как вызова открываются новые возможности, что ставит перед психологами задачу осмысления психологических характеристик, препятствующих и способствующих успешной адаптации к условиям COVID-19.

Одной из таких характеристик становится жизнестойкость, которая в зарубежной психологии обозначается в качестве общего ощущения того, что окружающая среда заставляет человека подходить к стрессовым ситуациям с любопытством, рассматривать их как значимые и интересные (вовлеченность), поддающиеся изменению (контроль), как возможность для развития (принятие риска) (Maddi, 2005). Важным в данной диспозиционной теории является то, что выделяется не только жизнестойкость как таковая, но и ее альтернативные характеристики, среди которых отчуждение, пассивность, беспомощность, катастрофизация происходящего (Maddi, 2006). Показано, что установки «вовлеченность», «контроль» и «принятие риска» определяют стиль личности, который связан с жизнестойкостью в целом и высокой эффективностью в широком диапазоне стрессовых ситуаций (Maddi, 2005; Maddi, 2006). В этом плане COVID-19 становится одной из таких стрессовых ситуаций, отличающихся неопределенностью, непредсказуемостью в краткосрочной и долгосрочной перспективах, неконтролируемостью (Trzebiński et al., 2020), травматичностью (Boyraz \& Legros, 2020), сложной комбинацией стрессоров (Chen \& Bonanno, 2020), многослойным риском (Krause, Freiling, Beets, \& Brossard, 2020).

Уникальность ситуации COVID-19 создает дополнительную нагрузку на личность и социальные группы, которые по-разному могут ее воспринимать и оценивать, и от которых требуется жизнестойкость для преобразования из угрожающей ситуации в ситуацию вызова. Именно жизнестойкость может служить той психологической характеристикой, которая способствует восприятию пандемии в качестве вызова. В исследованиях показано, что жизнестойкость является буфером для симптомов посттравматического стресса у матерей детей с неизлечимыми заболеваниями (Stoppelbein, McRae, \& Greening, 2017), опосредует психологическое благополучие (Alfred, Hammer, \& Good, 2014), является защитным фактором переживаний одиночества и депрессии ( $\mathrm{Ng} \&$ Lee, 2019), предотвращает проблемное употребление алкоголя (Kulak et al., 2020). Показано, что у жизнестойких лиц более высокое качество жизни, они более энергичны, оптимистичны, у них меньшее количество соматических жалоб (Manning, Williams, \& Wolfe, 1988). Также установлено, что жизнестойкость положительно связана 
ОДИНЦОВА М. А., РАДЧИКОВА Н. П., СТЕПАНОВА Л. В.

ОЦЕНКА ПАНДЕМИИ COVID-19 РОССИЯНАМИ С РАЗНЫМ УРОВНЕМ ЖИЗНЕСТОЙКОСТИ

РосСИЙСКИй пСИХологИЧЕСКИй ЖУРнАл, 2020, Т. 17, № 3, 76-88. doi: 10.21702/rpj.2020.3.6

СОЦИАЛЬНАЯ ПСИХОЛОГИЯ

с социальной поддержкой, активностью и эффективностью (Eschleman, Bowling, \& Alarcon, 2010). Совокупность таких факторов, как оптимизм, когнитивная гибкость, активное совладание, поддерживающая социальная сеть, забота о физическом благополучии, способствуют индивидуальной жизнестойкости, что может отражаться на устойчивости общества (Funk, 1992; lacoviello \& Charney, 2014). Люди с высоким уровнем жизнестойкости склонны интерпретировать стрессовые события как менее трудные, в результате чего снижается их влияние, и они с меньшей вероятностью оказывают негативное воздействие на здоровье (Kobasa, 1979).

Как видим, в различных исследованиях показаны специфичность ситуации COVID-19 и ее особое, в основном негативное, воздействие на население, однако исследований оценок COVID-19 россиянами с разным уровнем жизнестойкости не обнаружено. Данное исследование позволит предоставить важную информацию не только о негативных аспектах влияния пандемии, но и о способности россиян адаптироваться к текущей непростой ситуации. Всё это поможет внести вклад в создание программ психологической помощи, направленных на изменение негативных оценок в сторону поиска новых возможностей. Таким образом, целью исследования стало выявление оценок ситуации COVID-19 россиянами с разным уровнем жизнестойкости.

В исследованиях было подмечено, что не сами по себе события оказывают влияние на эффективное преодоление, а скорее то, как мы их воспринимаем, оцениваем и какое значение им придаем (Dryhurst et al., 2020), поэтому оценка данной ситуации (ее значимости, уровня сложности, стрессогенности и т. п.), эмоциональное отношение к ней (уровень выраженности страхов) во многом могут определять проявления жизнестойкости личности. Следовательно, можно предположить, что россияне с высоким уровнем жизнестойкости будут оценивать ситуацию COVID-19 как менее стрессогенную, т. е. как ситуацию вызова, в отличие от россиян со сниженным уровнем жизнестойкости, которые воспринимают ее как угрозу.

\section{Методы}

\section{Схема проведения исследования}

Исследование проводилось с 11 апреля по 4 июня 2020 г. в период самоизоляции. Большая часть выборки была набрана в апреле-мае 2020 г. Респондентам было предложено заполнить Google Форму, ссылка на которую была размещена на сайте факультета дистанционного обучения МГППУ и в социальных сетях. Исследование было добровольным. После завершения опроса, в социальных сетях и на сайте факультета было размещено приглашение для обсуждения первых результатов в обобщенном виде за виртуальным Круглым столом, который был организован кафедрой психологии и педагогики дистанционного обучения факультета дистанционного обучения МГППУ 29 июня 2020 г.

\section{Выборка}

В исследовании принял участие 421 житель России в возрасте от 18 до 78 лет (ср. возраст $=40,3 \pm 12,6$ лет), из них 340 женщин и 81 мужчина из Москвы ( $=247)$; Московской области $(\mathrm{N}=73)$, из других городов России $(\mathrm{N}=101)$.

\section{Методики исследования}

Для оценки COVID-19 респонденты заполняли специально разработанную анкету, предполагающую оценки по 11-балльной шкале Ликерта от 0 до 10 (максимальный балл) следующих аспектов ситуации: 
ОДИНЦОвА М. А., РАДЧИКОВА Н. П., СТЕПАНОВА Л. В.

ОЦЕНКА ПАНДЕМИИ COVID-19 РОССИЯНАМИ С РАЗНЫМ УРОВНЕМ ЖИЗНЕСТОЙКОСТИ

РосСиЙский психологИчЕский жУРнАл, 2020, Т. 17, № 3, 76-88. doi: 10.21702/rpj.2020.3.6

СОЦИАЛЬНАЯ ПСИХОЛОГИЯ

1) неопределенность, трудность, значимость, стрессогенность, непредсказуемость, неуправляемость и безвыходность;

2) степень влияния на разные сферы жизни (трудовую занятость, уровень заработной платы, уровень физической активности, качество отношений с близкими, качество социальных контактов);

3) выраженность различных страхов (умереть, заболеть, болезни близких и невозможности им помочь, болезни и смерти близких, остаться одному, остаться без работы, остаться без средств к существованию, испортить отношения с партнером);

4) собственные ресурсы для преодоления (физические, психологические, интеллектуальные, духовные, временные, творческие, материальные, социальные).

Дополнительно оценивалась возможность произошедшего стать источником полезного опыта (да/нет).

Для анализа вовлеченности, контроля, принятия риска в ситуации неопределенности и выделения групп с разным уровнем жизнестойкости использовался «Тест жизнестойкости» (Осин и Рассказова, 2013).

\section{Результаты}

Для выделения групп с разным уровнем жизнестойкости применялся кластерный анализ по методу $k$-средних. В качестве показателей для кластеризации использовались три шкалы теста жизнестойкости (вовлеченность, контроль, принятие риска) и общий балл жизнестойкости. Так как диапазоны изменения показателей были разными, данные предварительно были нормированы, т. е. приведены к такому виду, при котором среднее для каждого показателя стало равным нулю, а стандартное отклонение - единице. В результате кластеризации были выделены три группы: с высоким ( $N=169)$, средним $(N=181)$ и низким $(N=71)$ уровнями жизнестойкости. Для сравнения групп с разным уровнем жизнестойкости по оценкам различных аспектов ситуации COVID-19 (порядковые шкалы Ликерта) был использован Н-критерий Краскела - Уоллеса; для качественных показателей - критерий хи-квадрат Пирсона.

Статистический анализ показал, что россияне с разным уровнем жизнестойкости по-разному оценили ситуацию (табл. 1). Наиболее высокими оценками наделили неопределенность, сложность, непредсказуемость, неуправляемость, значимость и стрессогенность пандемии россияне с низким уровнем жизнестойкости. Достаточно высокие оценки дала группа со средним уровнем. Группа с высокой жизнестойкостью высокие оценки выставила лишь двум характеристикам: неопределенности и сложности. Несмотря на это, все три группы наиболее низкие оценки дали безвыходности ситуации.

Группы с разным уровнем жизнестойкости значимо различались в оценках влияния ситуации пандемии на трудовую занятость, уровень заработной платы, физической активности, качество отношений с близкими и качество социальных контактов (табл. 1). Степень воздействия ситуации на эти показатели оценивалась россиянами с разным уровнем жизнестойкости не так высоко, как сама ситуация пандемии. Здесь оценки колеблются от 6,8 (по степени воздействия на физическую активность в группе с низкой жизнестойкостью) до 2,7 (по степени влияния на качество отношений с близкими - в группе с высокой жизнестойкостью). На первый план в иерархии оценок в трех группах выходит оценка влияния ситуации на физическую активность. 
ОдИНЦОва М. А., РАДЧИкова Н. П., СТЕПАНОВа Л. В.

ОЦЕНКА ПАНДЕМИИ COVID-19 РОССИЯНАМИ С РАЗНЫМ УРОВНЕМ ЖИЗНЕСТОЙКОСТИ

РОССИЙСКИЙ ПСИХОЛОГИЧЕСКИЙ ЖХРнАл, 2020, Т. 17, № 3, 76-88. doi: 10.21702/rpj.2020.3.6

СОЦИАЛЬНАЯ ПСИХОЛОГИЯ

\begin{tabular}{|c|c|c|c|c|}
\hline \multirow{2}{*}{ Характеристики ситуации } & \multicolumn{3}{|c|}{ Жизнестойкость } & \multirow{2}{*}{$\begin{array}{l}\text { p, уровень } \\
\text { стат. } 3 \text { нач. }\end{array}$} \\
\hline & Высокая & Средняя & Низкая & \\
\hline Неопределенность & $6,7 \pm 2,4$ & $7,5 \pm 2,0$ & $7,9 \pm 1,7$ & 0,001 \\
\hline ТруАность & $6,7 \pm 2,4$ & $7,5 \pm 2,0$ & $7,9 \pm 1,7$ & $<0,001$ \\
\hline Значимость & $4,8 \pm 3,0$ & $5,7 \pm 2,6$ & $6,5 \pm 2,4$ & $<0,001$ \\
\hline Стрессогенность & $3,4 \pm 2,7$ & $4,9 \pm 2,7$ & $6,3 \pm 2,9$ & $<0,001$ \\
\hline Непредсказуемость & $5,6 \pm 3,1$ & $6,8 \pm 2,4$ & $7,1 \pm 2,5$ & $<0,001$ \\
\hline Неуправляемость & $4,6 \pm 3,2$ & $6,5 \pm 2,7$ & $7,1 \pm 2,8$ & $<0,001$ \\
\hline Безвыхо $\triangle$ НОсть & $3,1 \pm 2,6$ & $4,5 \pm 2,4$ & $5,5 \pm 2,5$ & $<0,001$ \\
\hline \multicolumn{5}{|c|}{ Степень влияния на различные сореры жизни } \\
\hline Трудовая занятость & $4,8 \pm 3,7$ & $6,1 \pm 3,3$ & $5,4 \pm 3,8$ & 0,005 \\
\hline Уровень заработной п^аты & $4,0 \pm 3,9$ & $5,2 \pm 3,9$ & $4,6 \pm 4,1$ & 0,018 \\
\hline Уровень оризической активности & $5,7 \pm 3,6$ & $6,8 \pm 3,2$ & $6,8 \pm 3,3$ & 0,005 \\
\hline Качество отношений с близкими & $2,7 \pm 2,9$ & $3,7 \pm 3,1$ & $5,1 \pm 2,9$ & 0,001 \\
\hline Качество социальных контактов & $4,9 \pm 3,3$ & $5,4 \pm 3,0$ & $6,5 \pm 2,9$ & 0,002 \\
\hline
\end{tabular}

Статистически значимые различия были получены и в оценках страхов (табл. 2). Все три группы наиболее высоко оценили страхи за близких: «заболеют мои близкие, и я не смогу им помочь» (от средних оценок в 5,5 балла в группе жизнестойких - до высоких в 7,7 балла в группе с низкой жизнестойкостью).

\begin{tabular}{|c|c|c|c|c|}
\hline \multirow{2}{*}{$\underline{\text { Страхи }}$} & \multicolumn{3}{|c|}{$\underline{\text { Жизнестойкость }}$} & \multirow{2}{*}{$\frac{\text { р, уровень стат. }}{\underline{3 \mathrm{Ha}_{4}}}$} \\
\hline & Высокая & Средняя & Низкая & \\
\hline Умереть & $2,1 \pm 2,5$ & $2,9 \pm 2,8$ & $3,1 \pm 2,09$ & 0,001 \\
\hline Заболеть & $2,8 \pm 2,8$ & $4,5 \pm 2,7$ & $4,5 \pm 3,0$ & $<0,001$ \\
\hline $\begin{array}{l}\text { Невозможность помочь } \\
\text { заболевшим близким }\end{array}$ & $5,5 \pm 3,4$ & $7,0 \pm 2,8$ & $7,7 \pm 2,7$ & $<0,001$ \\
\hline Мои близкие заболеют и умрут & $5,1 \pm 3,6$ & $6,7 \pm 3,0$ & $6,8 \pm 3,1$ & $<0,001$ \\
\hline
\end{tabular}


ОДИНЦОВА М. А., РАДЧИКОВА Н. П., СТЕПАНОВА Л. В.

ОЦЕНКА ПАНДЕМИИ COVID-19 РОССИЯНАМИ С РАЗНЫМ УРОВНЕМ ЖИЗНЕСТОЙКОСТИ

РосСиЙский психологИчЕский жУРнАл, 2020, Т. 17, № 3, 76-88. doi: 10.21702/rpj.2020.3.6

\section{СОЦИАЛЬНАЯ ПСИХОЛОГИЯ}

\begin{tabular}{|c|c|c|c|c|}
\hline \multirow{2}{*}{$\underline{\text { Страхи }}$} & \multicolumn{3}{|c|}{$\underline{\text { Жизнестойкость }}$} & \multirow{2}{*}{$\frac{\text { р, уровень стат. }}{\underline{3 \mathrm{Ha}} .}$} \\
\hline & Высокая & Средняя & Низкая & \\
\hline Остаться ОАНОМУ (ОАНОЙ) & $2,4 \pm 3,2$ & $3,7 \pm 3,3$ & $4,8 \pm 3,5$ & $<0,001$ \\
\hline Остаться без работы & $3,0 \pm 3,2$ & $4,4 \pm 3,2$ & $4,6 \pm 4,0$ & $<0,001$ \\
\hline $\begin{array}{l}\text { Остаться без среАств } \\
\text { к существованию }\end{array}$ & $3,6 \pm 3,3$ & $5,3 \pm 3,1$ & $5,8 \pm 3,7$ & $<0,001$ \\
\hline Испортить отношения с партнером & $1,6 \pm 2,5$ & $2,2 \pm 2,6$ & $2,9 \pm 3,0$ & 0,002 \\
\hline БуАущего & $2,7 \pm 2,8$ & $4,4 \pm 3,0$ & $6,5 \pm 2,6$ & $<0,001$ \\
\hline
\end{tabular}

Страх «мои близкие заболеют и умрут» занимает второе место в иерархии страхов и оценен в 5,1 балла жизнестойкой группой и в 6,8 балла - группой с низкой жизнестойкостью. Достаточно высоко данные страхи оценила группа со средним уровнем жизнестойкости. На третьем месте в иерархии страхов в группе россиян с низкой жизнестойкостью стоит страх будущего, в то время как данный страх занимает предпоследнее место в иерархии страхов жизнестойких россиян.

Анализ ответов на вопрос «Может ли произошедшее стать источником полезного опыта для Вас лично?» показал, что россияне с высоким и средним уровнями жизнестойкости чаще давали утвердительный ответ, в отличие от лиц с низким уровнем жизнестойкости $\left(\chi^{2}=32,95\right.$, при р < 0,001). Только в 12,7\% случаев группой с низкой жизнестойкостью данный опыт признавался (табл. 3).

Таблица 3

Ответы на вопрос «Может ли произошедшее стать источником полезного опыта Аля Вас ^ично?» россиян с разным уровнем жизнестойкости

$\begin{array}{ccc}\text { Жизнестойкость } & \underline{\mathrm{He \tau}} & \Delta \mathrm{a} \\ \text { Высокая } & 20,0 \% & 43,5 \% \\ \text { Средняя } & 38,3 \% & 43,8 \% \\ \text { Низкая } & 41,7 \% & 12,7 \%\end{array}$


ОДИНЦОВА М. А., РАДЧИКОВА Н. П., СТЕПАНОВА Л. В.

ОЦЕНКА ПАНДЕМИИ COVID-19 РОССИЯНАМИ С РАЗНЫМ УРОВНЕМ ЖИЗНЕСТОЙКОСТИ

РосСИЙСКИй пСИХологИЧЕСКИй ЖУРнАл, 2020, Т. 17, № 3, 76-88. doi: 10.21702/rpj.2020.3.6

СОЦИАЛЬНАЯ ПСИХОЛОГИЯ

Таким образом, оценки ключевых аспектов ситуации пандемии различаются у респондентов с разным уровнем жизнестойкости, причем чем ниже жизнестойкость, тем выше оцениваются негативные аспекты, выше уровень страхов, и тем реже данная ситуация рассматривается как вызов, который может стать источником полезного опыта.

Для определения того, какие ресурсы могут определять более высокую жизнестойкость, было проведено сравнение групп с разным уровнем жизнестойкости по оценкам всех ресурсов. Оказалось, что россияне с разным уровнем жизнестойкости оценивали собственные возможности для преодоления данной ситуации также по-разному (табл. 4). Духовные и интеллектуальные ресурсы в иерархии ресурсов трех групп лидируют. Самые низкие позиции занимают физические и материальные, оцененные: жизнестойкими россиянами - высокими и средними значениями; россиянами со средним уровнем жизнестойкости - средними; россиянами с низкой жизнестойкостью - средними и низкими баллами соответственно. В целом группа россиян с высоким уровнем жизнестойкости значительно выше оценила все вышеперечисленные возможности, в отличие от группы с низкой жизнестойкостью.

Таблица 4

Оценки своих ресурсов россиянами с разным уровнем жизнестойкости (среднее \pm стандартное отклонение)

\begin{tabular}{|lcccc|}
\hline \multicolumn{1}{c}{ Ресурсы } & \multicolumn{3}{c}{ Жизнестойкость } & р, уровеньстат. \\
Физические & Высокая & Срелняя & Низкая & $\underline{\text { знач. }}$ \\
Психологические & $6,8 \pm 2,8$ & $5,5 \pm 2,8$ & $4,4 \pm 2,9$ & $<0,001$ \\
Интеллектуальные & $7,9 \pm 2,4$ & $6,5 \pm 2,5$ & $5,1 \pm 2,9$ & $<0,001$ \\
Моральные/Ауховные & $8,0 \pm 2,2$ & $6,9 \pm 2,5$ & $5,8 \pm 2,8$ & $<0,001$ \\
Временные & $8,2 \pm 2,3$ & $7,0 \pm 2,5$ & $5,7 \pm 2,7$ & $<0,001$ \\
Творческие & $7,4 \pm 2,6$ & $6,2 \pm 2,8$ & $5,3 \pm 2,8$ & $<0,001$ \\
Материальные & $7,5 \pm 2,9$ & $6,1 \pm 2,9$ & $4,7 \pm 3,0$ & $<0,001$ \\
Социальные & $5,9 \pm 2,9$ & $5,0 \pm 2,9$ & $3,9 \pm 3,2$ & $<0,001$ \\
\hline
\end{tabular}

Для определения значимости влияния ресурсов на уровень жизнестойкости было проведено статистическое однофакторное прогнозирование показателя «низкая жизнестойкость» на основании разветвления одной вершины дерева методом CHAID (Груздев, 2018). Статистическая значимость влияния факторов на этот показатель осуществлялась с помощью критерия хи-квадрат Пирсона. Все факторы сортировались по убыванию значимости (статистика хи-квадрат). Статистический анализ показал (табл. 5), что все ресурсы вносят свой вклад в уровень жизнестойкости. Наиболее значимыми оказались моральные/духовные. 
ОДИНЦОВА М. А., РАДЧИКОВА Н. П., СТЕПАНОВА Л. В.

ОЦЕНКА ПАНДЕМИИ COVID-19 РОССИЯНАМИ С РАЗНЫМ УРОВНЕМ ЖИЗНЕСТОЙКОСТИ

РосСиЙский психологИчЕСКИй жУРнАл, 2020, Т. 17, № 3, 76-88. doi: 10.21702/rpj.2020.3.6

СОЦИАЛЬНАЯ ПСИХОЛОГИЯ

Их сниженный уровень (оценки ниже 7 баллов) характерен только для 9,4\% респондентов со средней и высокой жизнестойкостью, но для более трети $(35,2 \%)$ респондентов с низкой жизнестойкостью. Так как относительный риск представляет собой отношение риска наступления определенного события у лиц, подвергшихся воздействию фактора риска, по отношению к группе без воздействия фактора, то относительный риск = 3,76 говорит о том, что недостаток моральных/духовных ресурсов повышает риск попасть в группу с низкой жизнестойкостью в среднем почти в 4 раза. Сниженные оценки психических, творческих и интеллектуальных ресурсов повышают риск попасть в группу с низкой жизнестойкостью примерно в 3 раза. Действительно, ограничения в психических ресурсах присущи только 9,5\% респондентов из групп со средней и высокой жизнестойкостью, но 30,4\% респондентов из группы с низкой жизнестойкостью; ограничения в творческих ресурсах присущи только 8,0\% респондентов из групп со средней и высокой жизнестойкостью, но 26,9\% респондентов из группы с низкой жизнестойкостью.

\section{Таблица 5}

Факторы влияния на показатель «низкая жизнестойкость» (оценки абсолютных рисков, изменение риска, относительный риск) в порядке убывания значимости

\begin{tabular}{|c|c|c|c|}
\hline \multirow{3}{*}{ Pecypсы } & \multicolumn{2}{|c|}{ Частота (риск \%) } & Относительный \\
\hline & \multicolumn{2}{|c|}{ Жизнестойкость } & риск $195 \%$ \\
\hline & Высокая и средняя & Низкая & интервал) \\
\hline Моральные/Ауховные $<7,0$ & $28(9,4 \%)$ & $43(35,2 \%)$ & $3,76(2,46 ; 5,77)$ \\
\hline Психические < 7,0 & $26(9,5 \%)$ & $45(30,4 \%)$ & $3,19(2,06 ; 4,95)$ \\
\hline Творческие < 7,0 & $18(8,0 \%)$ & $53(26,9 \%)$ & $3,35(2,03 ; 5,52)$ \\
\hline Интел^ектуальные < 7,0 & $32(10,9 \%)$ & $39(30,5 \%)$ & $2,79(1,84 ; 4,24)$ \\
\hline Социальные < 5,0 & $38(12,0 \%)$ & $33(31,7 \%)$ & $2,65(1,76 ; 3,99)$ \\
\hline Временные $<7,0$ & $23(9,8 \%)$ & $48(25,8 \%)$ & $2,64(1,67 ; 4,17)$ \\
\hline Материальные < 3,0 & $45(13,4 \%)$ & $26(30,6 \%)$ & $2,28(1,50 ; 3,48)$ \\
\hline Физические < 6,0 & $26(10,9 \%)$ & $45(24,6 \%)$ & $2,25(1,45 ; 3,50)$ \\
\hline
\end{tabular}

Наименее важными оказались материальные и физические ресурсы: их недостаток повышает риск попасть в группу с низкой жизнестойкостью в среднем только в 2 раза. Если ограничиться самыми осторожными оценками и брать во внимание только нижнюю границу доверительного интервала, то можно заключить, что наиболее важны моральные/духовные, психические и творческие ресурсы, т. к. их недостаток увеличивает риск попасть в группу с низкой жизнестойкостью примерно в 2 раза (от 2,03 до 2,46 раз). 
ОДИНЦОВА М. А., РАДЧИКОВА Н. П., СТЕПАНОВА Л. В.

ОЦЕНКА ПАНДЕМИИ COVID-19 РОССИЯНАМИ С РАЗНЫМ УРОВНЕМ ЖИЗНЕСТОЙКОСТИ

РосСИЙСКИЙ пСИХОЛОГИЧЕСКИЙ ЖУРнАл, 2020, Т. 17, № 3, 76-88. doi: 10.21702/rpj.2020.3.6

СОЦИАЛЬНАЯ ПСИХОЛОГИЯ

\section{Обсуждение результатов}

Жизненный опыт разных людей вносит свой вклад в оценивание ситуации неопределенности, ярким примером которой является COVID-19, заставляет переосмысливать прошлое, настоящее, будущее. Пандемия коронавируса является лучшей возможностью для переосмысления опыта россиян с разным уровнем жизнестойкости и дает возможность поделиться этим опытом. Выделение групп с разным уровнем жизнестойкости позволило глубже посмотреть на данную ситуацию, придать ей более четкое обозначение на основании тех оценок, которые давали сами респонденты. Все три группы россиян однозначно указали на то, что ситуация пандемии является неопределенной и достаточно сложной, оказывающей влияние на физическую активность, чему способствовала вынужденная самоизоляция. Больше всего россияне опасаются за своих близких, но уверены в своих духовных ресурсах, которые занимают первое место в иерархии обозначенных ресурсов.

Исследование показало, что большинство россиян входит в группы с высоким и средним уровнями жизнестойкости: $40 \%$ и $43 \%$ соответственно. Группу риска составляют $17 \%$. Россияне с высокой жизнестойкостью не склонны оценивать ситуацию COVID-19 как катастрофическую. Признается, что она неопределенная и трудная, но подконтрольная. Жизнестойкие россияне высоко оценили собственные возможности: интеллектуальные, духовные, психологические, творческие, физические, социальные и материальные. Они считают, что случившееся вполне может стать источником полезного опыта.

Группа со средним уровнем жизнестойкости заинтересована в происходящем, мотивирована, получает удовольствие от деятельности. Оценивает данную ситуацию как неопределенную, сложную, непредсказуемую, неуправляемую, оказывающую влияние на физическую активность, отмечает некоторое ее воздействие на трудовую занятость, однако не считает ее безвыходной. Данная группа обеспокоена только страхами за своих близких, достаточно высоко оценила свои духовные, интеллектуальные и психологические возможности.

Ситуация COVID-19 для группы с низкой жизнестойкостью оказалась высоко неопределенной, сложной, непредсказуемой, достаточно значимой и не поддающейся контролю, оказывающей влияние не только на физическую активность, но и на качество социальных контактов. Кроме выраженных страхов за своих близких, данной группе свойственен страх будущего. Они в меньшей степени уверены в своих возможностях, и многие не принимают ситуацию в качестве опыта. Однако для них данная ситуация всё же не становится столь безвыходной.

Полученные результаты находятся в полном согласии с представлениями о жизнестойкости как способности личности выдерживать стрессовые ситуации, сохраняя при этом внутреннюю сбалансированность без снижения успешности деятельности, и говорят о прогностической ценности данного конструкта. Ограничением данного исследования является недостаточный объем в выборке мужчин. Перспективным видится сравнительный анализ оценок ситуации COVID-19 представителями разных поколений, с разным уровнем образования и разным социальным статусом.

\section{Выводы}

Ситуация пандемии COVID-19 - это сложная комбинация стрессоров, которая отличается неопределенностью, сложностью, непредсказуемостью, неуправляемостью, значимостью и требует от личности и социальных групп жизнестойкости - для ее преобразования из ситуации угрозы в ситуацию вызова. При переживании пандемии как угрозы происходит обострение 
ОДИНЦОвА М. А., РАДЧИКОВА Н. П., СТЕПАНОВА Л. В.

ОЦЕНКА ПАНДЕМИИ COVID-19 РОССИЯНАМИ С РАЗНЫМ УРОВНЕМ ЖИЗНЕСТОЙКОСТИ

РосСиЙский психологИчЕский жУРнАл, 2020, Т. 17, № 3, 76-88. doi: 10.21702/rpj.2020.3.6

СОЦИАЛЬНАЯ ПСИХОЛОГИЯ

множества кризисных явлений в обществах, при восприятии ее как вызова открываются новые возможности. Жизнестойкость становится одной из центральных психологических характеристик, способствующих восприятию COVID-19 в качестве вызова.

Большинство россиян восприняли пандемию в качестве вызова своим возможностям (духовным, интеллектуальным, психологическим, творческим и т. п.). В группу риска попали $17 \%$ россиян, которые восприняли данную ситуацию в качестве угрозы, опасаются за свое будущее, не принимают ее, ниже оценивают свои возможности, больше других нуждаются в социальных контактах, однако не считают ситуацию COVID-19 безвыходной. Именно данной группе требуются психологическая помощь, которая направлена на просвещение, основанное на результатах научных исследований (Aven \& Bouder, 2020), и адресная работа по изменению пессимистичных оценок. В условиях пандемии это возможно через открытые онлайн-мероприятия. Серия таких мероприятий с самого начала пандемии была реализована в МГППУ. Таким образом, пандемия COVID-19, как неожиданное событие, стала проверкой устойчивости россиян как способности успешно использовать внутренние и внешние ресурсы для решения проблем.

\section{Литература}

Бойко, О. М., Медведева, Т. И., Ениколопов, С. Н., Воронцова, О. Ю. и Казьмина, О. Ю. (2020). Психологическое состояние людей в период пандемии COVID-19 и мишени психологической работы. Психологические исследования, 13, 1. Доступ 24 августа 2020, источник http://psystudy.ru

Груздев, А. (2018). Прогнозное моделирование в IBM SPSS Statistics, R и Python. Memoд деревьев решений и случайный лес. ДМК-Пресс.

Осин, Е. Н. и Рассказова, Е. И. (2013). Краткая версия теста жизнестойкости: психометрические характеристики и применение в организационном контексте. Вестник Московского университета. Серия 14. Психология, 2, 147-165.

Тхостов, А. Ш. и Рассказова, Е. И. (2020). Психологическое содержание тревоги и профилактики в ситуации инфодемии: защита от коронавируса или «порочный круг» тревоги? Консультативная психология и психотерапия, 28(2), 70-89. doi: 10.17759/срр.2020280204

Abdullah, I. (2020). COVID-19: Threat and fear in Indonesia. Psychological Trauma: Theory, Research, Practice and Policy, 12(5), 488-490. doi: 10.1037/tra0000878

Alfred, G. C., Hammer, J. H., \& Good, G. E. (2014). Male student veterans: Hardiness, psychological well-being, and masculine norms. Psychology of Men \& Masculinities, 15(1), 95-99. doi: 10.1037/a0031450

AlHumaid, J., Ali, S., \& Farooq, I. (2020). The psychological effects of the COVID-19 pandemic and coping with them in Saudi Arabia. Psychological Trauma: Theory, Research, Practice, and Policy, 12(5), 505-507. doi: 10.1037/tra0000623

Aven, T., \& Bouder, F. (2020). The COVID-19 pandemic: How can risk science help? Journal of Risk Research. doi: 10.1080/13669877.2020.1756383

Berger, E., \& Reupert, A. (2020). The COVID-19 pandemic in Australia: Lessons learnt. Psychological Trauma: Theory, Research, Practice, and Policy, 12(5), 494-496. doi: 10.1037/tra0000722

Boyraz, G., \& Legros, D. N. (2020). Coronavirus disease (COVID-19) and traumatic stress: Probable risk factors and correlates of posttraumatic stress disorder. Journal of Loss and Trauma, 25(6-7), 503-522. doi: 10.1080/15325024.2020.1763556 
ОДИНЦОВА М. А., РАДЧИКОВА Н. П., СТЕПАНОВА Л. В.

ОЦЕНКА ПАНДЕМИИ COVID-19 РОССИЯНАМИ С РАЗНЫМ УРОВНЕМ ЖИЗНЕСТОЙКОСТИ

РосСИЙСКИЙ пСИХОЛОГИЧЕСКИЙ ЖУРнАл, 2020, Т. 17, № 3, 76-88. doi: 10.21702/rpj.2020.3.6

СОЦИАЛЬНАЯ ПСИХОЛОГИЯ

Campbell, A. M. (2020). An increasing risk of family violence during the Covid-19 pandemic: Strengthening community collaborations to save lives. Forensic Science International, 2, 1-3. doi: 10.1016/.jsir.2020.100089

Caqueo-Urízar, A., Urzúa, A., Aragón-Caqueo, D., Charles, C. H., El-Khatib, Z., Otu, A., \& Yaya, S. (2020). Mental health and the COVID-19 pandemic in Chile. Psychological Trauma: Theory, Research, Practice, and Policy, 12(5), 521-523. doi: 10.1037/tra0000753

Chen, S., \& Bonanno, G. A. (2020). Psychological adjustment during the global outbreak of COVID-19: A resilience perspective. Psychological Trauma: Theory, Research, Practice, and Policy, 12(S1), S51-S54. doi: 10.1037/tra0000685

Cohn-Schwartz, E., Sagi, D., O'Rourke, N., \& Bachner, Y. G. (2020). The coronavirus pandemic and Holocaust survivors in Israel. Psychological Trauma: Theory, Research, Practice, and Policy, 12(5), 502-504. doi: 10.1037/tra0000771

Dryhurst, S., Schneider, C. R., Kerr, J., Freeman, A. L. J., Recchia, G., van der Bles, A. M., ... van der Linden, S. (2020). Risk perceptions of COVID-19 around the world. Journal of Risk Research. doi: 10.1080/13669877.2020.1758193

Durodié, B. (2020). Handling uncertainty and ambiguity in the COVID-19 pandemic. Psychological Trauma: Theory, Research, Practice, and Policy, 12(S1), S61-S62. doi: 10.1037/tra0000713

El Maarouf, M. D., Belghazi, T., \& El Maarouf, F. (2020). COVID - 19: A Critical Ontology of the present. Educational Philosophy and Theory. doi: 10.1080/00131857.2020.1757426

Eschleman, K. J., Bowling, N. A., \& Alarcon, G. M. (2010). A meta-analytic examination of hardiness. International Journal of Stress Management, 17(4), 277-307. doi: 10.1037/a0020476

Estes, K. D., \& Thompson, R. R. (2020). Preparing for the aftermath of COVID-19: Shifting risk and downstream health consequences. Psychological Trauma: Theory, Research, Practice, and Policy, 12(S1), S31-S32. doi: 10.1037/tra0000853

Faris, D. (2020). Coronavirus' looming psychological crisis. The Week. Retrieved from https:// theweek.com/articles/903343/coronavirus-looming-psychological-crisis

Fitzpatrick, K. M., Harris, C., \& Drawve, G. (2020). Fear of COVID-19 and the mental health consequences in America. Psychological Trauma: Theory, Research, Practice, and Policy, 12(S1), S17-S21. doi: 10.1037/tra0000924

Funk, S. C. (1992). Hardiness: A review of theory and research. Health Psychology, 11(5), 335-345. doi: $10.1037 / 0278-6133.11 .5 .335$

lacoviello, B. M., \& Charney, D. S. (2014). Psychosocial facets of resilience: Implications for preventing posttrauma psychopathology, treating trauma survivors, and enhancing community resilience. European Journal of Psychotraumatology, 5(1). doi: 10.3402/ejpt.v5.23970

lqbal, N., \& Dar, K. A. (2020). Coronavirus disease (COVID-19) pandemic: Furnishing experiences from India. Psychological Trauma: Theory, Research, Practice, and Policy, 12(S1), S33-S34. doi: $10.1037 /$ tra0000770

Kobasa, S. C. (1979). Stressful life events, personality, and health: An inquiry into hardiness. Journal of Personality and Social Psychology, 37(1), 1-11. doi: 10.1037/0022-3514.37.1.1

Krause, N. M., Freiling, I., Beets, B., \& Brossard, D. (2020). Fact-checking as risk communication: The multi-layered risk of misinformation in times of COVID-19. Journal of Risk Research. doi: 10.1080/13669877.2020.1756385

Kulak, J. A., Homish, D. L., Hoopsick, R. A., Fillo, J., Bartone, P. T., \& Homish, G. G. (2020). Hardiness protects against problematic alcohol use in male, but not female, soldiers. Psychological Services. doi: $10.1037 /$ ser0000409 
ОДИНЦОВА М. А., РАДЧИКОВА Н. П., СТЕПАНОВА Л. В.

ОЦЕНКА ПАНДЕМИИ COVID-19 РОССИЯНАМИ С РАЗНЫМ УРОВНЕМ ЖИЗНЕСТОЙКОСТИ

РосСиЙский психологИчЕский жУРнАл, 2020, Т. 17, № 3, 76-88. doi: 10.21702/rpj.2020.3.6

СОЦИАЛЬНАЯ ПСИХОЛОГИЯ

Maddi, S. R. (2005). On hardiness and other pathways to resilience. American Psychologist, 60(3), 261-262. doi: 10.1037/0003-066X.60.3.261

Maddi, S. R. (2006). Hardiness: The courage to grow from stresses. The Journal of Positive Psychology, 1(3), 160-168. doi: 10.1080/17439760600619609

Manning, M. R., Williams, R. F., \& Wolfe, D. M. (1988). Hardiness and the relationship between stressors and outcomes. Work \& Stress, 2(3), 205-216. doi: 10.1080/02678378808259168

Marazziti, D., Pozza, A., Di Giuseppe, M., \& Conversano, C. (2020). The psychosocial impact of COVID-19 pandemic in Italy: A lesson for mental health prevention in the first severely hit European country. Psychological Trauma: Theory, Research, Practice, and Policy, 12(5), 531-533. doi: $10.1037 /$ tra0000687

Miller, E. D. (2020). The COVID-19 pandemic crisis: The loss and trauma event of our time. Journal of Loss and Trauma, 25(6-7), 560-572. doi: 10.1080/15325024.2020.1759217

Ng, S. M., \& Lee, T. M. C. (2019). The mediating role of hardiness in the relationship between perceived loneliness and depressive symptoms among older. Aging \& Mental Health, 24(5), 805-810. doi: 10.1080/13607863.2018.1550629

Nguyen, T. H. D., \& Vu, D. C. (2020). Impacts of the COVID-19 pandemic upon mental health: Perspectives from Vietnam. Psychological Trauma: Theory, Research, Practice, and Policy, 12(5), 480-481. doi: 10.1037/tra0000694

PeConga, E. K., Gauthier, G. M., Holloway, A., Walker, R. S. W., Rosencrans, P. L., Zoellner, L. A., \& Bedard-Gilligan, M. (2020). Resilience is spreading: Mental health within the COVID-19 pandemic. Psychological Trauma: Theory, Research, Practice, and Policy, 12(S1), S47-S48. doi: 10.1037/tra0000874

Prime, H., Wade, M., \& Browne, D. T. (2020). Risk and resilience in family well-being during the COVID-19 pandemic. American Psychologist, 75(5), 631-643. doi: 10.1037/amp0000660

Reger, M. A., Stanley, I. H., \& Joiner, T. E. (2020). Suicide mortality and coronavirus disease 2019 - A perfect storm? JAMA Psychiatry. doi: 10.1001/jamapsychiatry.2020.1060

Rodríguez-Rey, R., Garrido-Hernansaiz, H., \& Collado, S. (2020). Psychological impact of COVID-19 in Spain: Early data report. Psychological Trauma: Theory, Research, Practice, and Policy, 12(5), 550-552. doi: 10.1037/tra0000943

Shigemura, J., \& Kurosawa, M. (2020). Mental health impact of the COVID-19 pandemic in Japan. Psychological Trauma: Theory, Research, Practice, and Policy, 12(5), 478-479. doi: 10.1037/ tra0000803

Stoppelbein, L., McRae, E., \& Greening, L. (2017). A longitudinal study of hardiness as a buffer for posttraumatic stress symptoms in mothers of children with cancer. Clinical Practice in Pediatric Psychology, 5(2), 149-160. doi: 10.1037/cpp0000168

Trzebiński, J., Cabański, M., \& Czarnecka, J. Z. (2020). Reaction to the COVID-19 pandemic: The influence of meaning in life, life satisfaction, and assumptions on world orderliness and positivity. Journal of Loss and Trauma, 25(6-7), 544-557. doi: 10.1080/15325024.2020.1765098

Конфликт интересов отсутствует 